Vol. 11, No. 40, July, 2016, 1101-1111

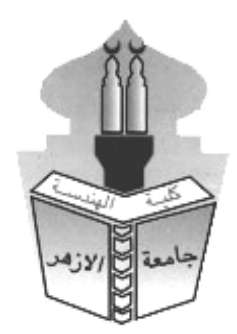

\title{
UTILIZATION OF USING CEMENT KILN DUST (CKD) AS A SURFACIAL CLAY SOIL STABILIZER UNDERNEATH ROADS
}

\author{
Mohammad Hasan Alawi \\ Civil Engineering Dept. Makkah, Ksa, Kingdom Of Saudi Arabia
}

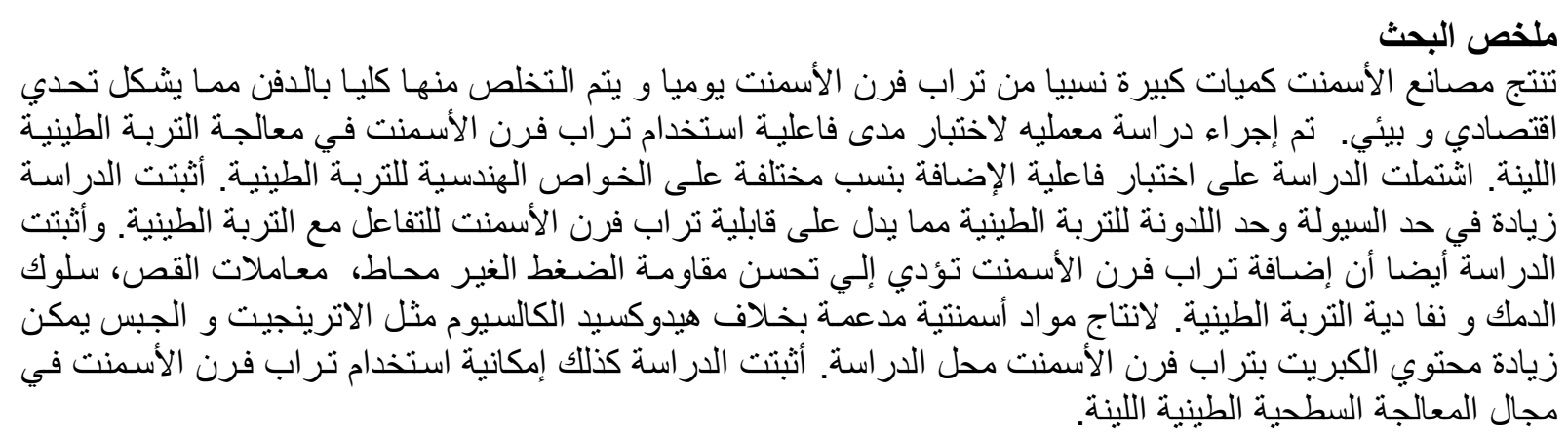

\begin{abstract}
Cement kiln dust (CKD) is produced at relatively high rates at cement industry plants all over Kingdom of Saudi Arabia (KSA) causing economical and environmental problems. A laboratory study was conducted to investigate the effectiveness of using CKD as sacrificial stabilizer of cohesive soil under roads. The study included measuring the effect of CKD addition with different percentages on soil properties. Significant increase in Liquid and plastic limits were recorded indicating reactivity of CKD with clay soil. CKD addition to clay soil significantly improved stress strain relationship, unconfined compressive strength (UCS), shear strength, compaction behavior and permeability of clay soil. The study indicated the effectiveness of applying CKD produced at Yanbu Cement Plant as a stabilizer of clay soil in sacrificial stabilization. Additing CKD to clay soil significantly improves the permeability of clay soil.
\end{abstract}

Key words: cement kiln dust, clay soil , compaction , liquid limit, pavement, , plastic limits, , shear strength

\section{INTROUDUCTION}

Cement Kiln Dust (CKD) is a finally divided, dry particle material drained from cement kiln by exhaust gases and captured by the kiln's air pollution system, Peethamparan et al., 2008. The manufacturing technology, type and quantity of raw materials (including limestone, shale, sand and iron) determine the chemical composition and physical properties of CKD. In general CKD is composed of particles of clinker, un-reacted and partially, calcite raw material and the fuel ash enriched with alkali sulfates, Sreekrishnavilasam et al 2007, Aheln et al, 1993, and Dyer et al, 1999. The dust is produced from cement plants all over the world in relatively high quantities.

Although, modern advances in cement manufacturing technology resulted in considerable reduction of CKD quantities, there rates may still be considered as a industry by pass being produced in relatively large scale. The majority of Saudi cement manufacturing plants 
transports CKD to land filling areas with considerable transportation costs, environmental pollution problems and certainly in an uneconomical way of dealing with this problem.

The available literature, indicate that there is promising results of using CKD in a several geotechnical, civil, structural and agricultural applications. In the field of geotechnical engineering McCoy and Kriner, 1971 ,investigate the effectiveness of using CKD as a soil stabilizer. They applied CKD with different lime contents to soil with different plasticity. The results indicated that 7 days unconfined compressive strength (UCS) of treated soil was higher than that treated with Portland cement or lime. Baghdadi, 1990 and Baghdadi et al, 1995, investigated using CKD as a stabilizer of Kaolinite. The results indicated that after 28 days UCS of $16 \%$ CKD treated soil increased 5 times compared to untreated soil. It was indicated that as the treatment ratio increases a corresponding increase in liquid limit (LL), plastic limit ( PL) and plasticity index (PI). This was agreed with Zaman et al, 1992, and Miller and Azad, who stated that LL increases with CKD ratio for low plasticity clay while decreases for high plasticity clay. Hilt and Davidson, 1960, indicated that change of PL and not LL may be considered as an indicator of the potential for stabilizing the soil. Sreekrishavilasam et al, 2007, conducted an experimental study to investigate the effectiveness of different samples of fresh and land filled CKD. It was concluded that relevance of CKD as a soil stabilizer depends on free lime $(\mathrm{CaO})$ content. It was also concluded that additing of CKD to cohesive soil changes PL which is a good indicator of its reactivity with soil. The researchers also indicated that addition of CKD to cohesive soil of very high water content makes soil compactable and further addition of small amounts of Portland cement by $1 \%$ significantly improved the strength of CKD-soil mixture. Peethamaran et al, 2008, conducted a similar study with more detailed investigation of the reactivity of CKD with cohesive soil using X-Ray diffraction analysis and scanning electron microscope. They concluded that CKD with high free lime content when hydrated produces significant amounts of cementious compounds (e.g. calcium hydroxide, syngenite and ettringite), however these compounds where in case of absent or present in much smaller quantities on hydration of CKD with low free lime content. For high free lime content CKD amount of cementious compounds increased with curing time. It was also concluded that CKD with high free lime content exhibited higher strength and hydration temperature when mixed with clay soil.

Composition of CKD is significantly varies according to manufacturing techniques, type and amount of raw materials. This necessitates conducting a detailed research study to determine usefulness of using the produced CKD as a soil stabilizer. However, X-Ray diffraction analysis on a sample of the produced CKD of the plant which will be presented hereafter in Table (1) indicates relatively high free lime content which reflects the ability of using it in the field of soil stabilization.

Flexible pavements are the predominant type of roads used in Saudi Arabia and other parts of the worlds, where the majority of paved surfaces fall under the overall category of flexible pavements Alawi, 2000. Flexible pavements may be classified as a conventional or a full depth pavement. Conventional flexible pavements are layered systems that consist of an asphalt mixture (wearing course) over one or more of granular layers (base and sub-base) which, together are constructed over the sub-grade soil. Clay soil may exist in regions of sedimentary soil existing at valley located in flood pathways. Such compressible layers encounter unfavorable engineering properties for sub-grade soil. Figure (1) shows a cross section of flexible pavement structure. Granular base and sub-base layers are essential components of a flexible pavement system where their function is to reduce traffic induced stresses in the pavement structure and to minimize rutting in the base, sub-base and sub grades. Effectiveness of using industry by-products such as CKD in stabilizing such comprisable layers will be investigated in this research. 


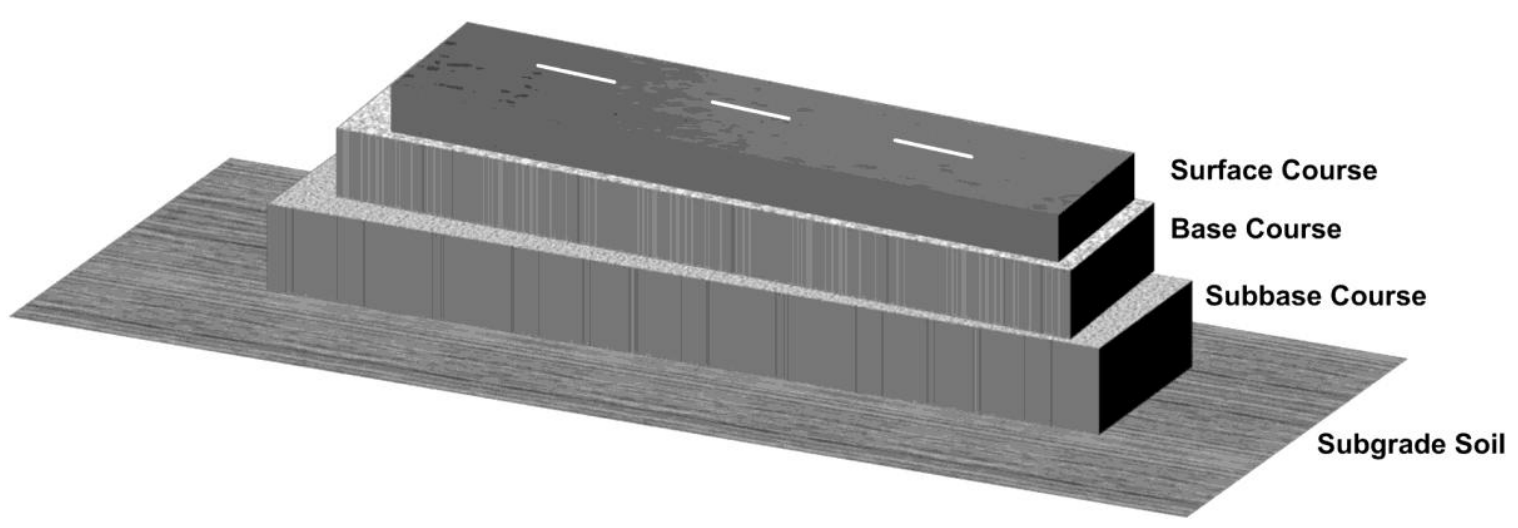

Fig. (1) Cross section of flexible asphalt concrete pavement

\section{MATERIALS}

\subsection{Clay Soil}

The soil tested in this research was extracted from an excavated site at a depth of 3.0 $\mathrm{m}$ of a clay soil layer. The soil was dried and pulverized. Constituent ratios of clay, silt and fine sand are 48, 44 and 8\%, respectively. The Liquid limit, Plastic limit and Plasticity index and specific gravity are $62.8 \%, 22.43 \%, 40.37 \%$ and 2.68 , respectively. The recorded maximum dry density was $18 \mathrm{kN} / \mathrm{m}^{3}$ and the optimum moisture content was $15 \%$. The measured $\mathrm{pH}$ was 5.0. According to unified soil classification system (USCS) soil may be classified as high plasticity clay $(\mathrm{CH})$

\subsection{Cement Kiln Dust}

Table (1) illustrates ratios of oxides composition of CKD collected along a production date. As can be observed from Table (1) CKD has high free lime content, and the sulphate content is relatively small, so formation of cementeous compound of ettringete is questionable.

Table (1) Oxides composition \% of CKD from Yanbu plant along a production day.

\begin{tabular}{clllllll}
\hline Oxide & $\mathrm{SiO}_{2}$ & $\mathrm{Fe}_{2} \mathrm{O}_{3}$ & $\mathrm{CaO}$ & $\mathrm{MgO}$ & $\mathrm{K}_{2} \mathrm{O}$ & $\mathrm{SO}_{3}$ & $\mathrm{Cl}$ \\
\hline$\%$ & $14-20$ & $1.5-2.5$ & $35-45$ & $0.9-2$ & $4-10$ & $3-7$ & $4-9$ \\
\hline
\end{tabular}

A fresh sample of CKD from the manufacture outlet was put in a plastic bag and brought to the soil laboratory for the testing program. Grain size distribution analysis was carried out on the sample. From this analysis, the effective size $\mathrm{D}_{10}=4.0 \mu \mathrm{m}, \mathrm{D}_{30}=7.0 \mu \mathrm{m}$, $\mathrm{D}_{60}=8.0 \mu \mathrm{m}, \mathrm{D}_{90}=70.0 \mu \mathrm{m}$, uniformity coefficient $\mathrm{C}_{\mathrm{u}}=2.0$ and coefficient of gradation $\mathrm{C}_{\mathrm{c}}=$ 1.53 .

\section{TESTING PROGRAM \\ 3.1. Sample Preparation}

Pulverized clay powder was mixed with water of about $60 \%$ of dry unit weight. Soil slurry was then consolidated in 10 inch $(25.4 \mathrm{~cm})$ diameter Rowe consolidation cell until reaching the clay consistency which was checked by cone pentameter. To measure the effect of additing CKD on consistency of clay soil, liquid limit and plastic limit were determined for mixed soil with different CKD mixing ratios. In order to investigate the formation of hydration cementious compounds upon moisture addition to CKD water was added to the three samples used for X-ray diffraction analysis with $30 \%$ addition ratios. Samples were stored in nylon bags for 1,7 and 28 days until being analyzed by X-Ray. Prior to X-Ray analysis samples were dried for 24 hours at $70^{\circ} \mathrm{C}$ and then ground to its original size. Samples examined by scanning electron microscope (SEM) were also prepared by oven drying and fracturing into cubic samples of about $1.0 \mathrm{~cm}$ dimension of reveal and clean fractured surface 


\subsection{Testing Procedures:}

Various tests were carried out according to Bowles, 1978. Liquid and plastic limits were investigated for plain untreated samples and of samples treated with CKD of different ratios. Unconfined compression strength (UCS) was determined for neat and CKD treated soft soil samples. CKD of ratios of 10,15, 20, 25 and $30 \%$ by dry weight was added and mixed with soft clay samples and left to overnight. Soil Cylinders of $35 \mathrm{~mm}$ diameter and $70 \mathrm{~mm}$ height were prepared by compacting neat and treated soil into cylindrical mould immediately after addition of CKD. Samples were compacted to maximum dry density. Samples were then extracted from the mould by unscrewing the two parts of the mould. Cylinders were then stored in nylon bags and kept in a closed wooden box for curing periods of 3, 7 and 28 days. Samples were then tested in the unconfined compression apparatus to determine their unconfined compressive stress (UCS) and the stress strain relationship of samples.

To determine the effect of CKD on shear strength of cohesive soil direct shear test were carried on neat and treated samples with different ratios of CKD. Soil Cylinders of $60 \mathrm{~mm}$ diameter and $40 \mathrm{~mm}$ height were prepared in a manner similar to that used in preparing samples for UCS test. In order to compare moisture density relation of neat and treated soil Standard Proctor Tests were carried out. Soft soil samples was mixed with different ratios of CKD.

To measure the effect of CKD on the permeability of clay soil, falling head permeability tests were carried out on untreated and treated soil samples. Samples were prepared by compaction to the range of $90 \%$ maximum dry density using a standard Proctor drop hammer. Samples were compacted in four layers in the mould of permeability apparatus.

In order to investigate the formation of hydration cementious compounds upon moisturing of CKD X-Ray diffraction analysis was conducted using Siemens D-500 diffractometer. The source of radiation was $\mathrm{CuK \alpha}$ with the tube powered to $50 \mathrm{kV}$ at $30 \mathrm{~mA}$. Dried powder samples were scanned from 3 to $65^{\circ} 2$-theta at $0.02^{\circ}$ step size. The interpretation of the X-Ray pattern for the presence of crystalline components carried out by usual methods involving determination of each of the peaks present in the X-Ray pattern to one or more of the potential crystalline phases. Untreated and treated clay soil samples were examined using Scanning Electron Microscope (SEM) with a relatively low magnifying scale of 2800 . This study aimed to just viewing a fractured surface in case of untreated and treated samples to account for the change in soil permeability expected upon treatment, so the study was limited to analyze two samples only. Samples were coated with gold thin film. Imaging was performed using an FEL Nova Nano SEM field emission scanning electron microscope.

\section{RESULTS AND DISCUSSION \\ 4.1 Consistency Limits}

Table (2) shows the liquid and plastic limits for untreated and treated soil with different CKD mixing ratios. As can be observed from this table, CKD addition to clay soil results in a significant increase in Liquid limit (LL) within an average range of $2.7 \%$ per each $5 \%$ increase in CKD addition ratio. A similar trend was observed with plastic limit (PL) but with smaller increase ratio of $1.8 \%$. A similar trend with relatively higher PL increasing ratios ranging up to $4-5 \%$ has been observed with CKD of relatively high free lime content of $50.4 \%$ according to Sreekrishnavilasam et al, 2007. However, PL was nearly unchanged in case of using CKD with lower free lime content of $44.9 \%$.

Table (2) Liquid, plastic limits and plasticity index of untreated and treated samples with different CKD

\begin{tabular}{l|c|c|c|c|c|c}
\multicolumn{1}{c}{ CKD (\%) } & 0 & 10 & 15 & 20 & 25 & 30 \\
\hline Liquid Limit LL (\%) & 41.8 & 44.6 & 47.5 & 50.0 & 53.8 & 56.4 \\
\hline Plastic Limit PL (\%) & 18 & 19.5 & 21.1 & 23.1 & 24.9 & 26.7 \\
\hline Plasticity Index PI (\%) & 23.8 & 25.1 & 26.4 & 26.9 & 28.9 & 29.7 \\
\hline
\end{tabular}




\subsection{Unconfined Compressive Strength (UCS)}

Fig. (2) Illustrates the unconfined stress strain relationship of untreated and treated unconfined sample with different CKD addition ratios of 10, 15, 20 and 30\% after 28 days curing period. As can be seen from this figure, additing CKD to clay soil significantly increases initial stiffness. Initial tangent modulus of untreated, $10 \%$ and the remaining higher addition ratios are 8000, 20000 and $30000 \mathrm{kPa}$, respectively. Ultimate UCS values were noticed to be significantly increase with increase of treatment ratio. The recorded UCS increasing ratios were 10, 33, 53 and 74\% compared to untreated sample for CKD ratios of 10, 15, 20 and $30 \%$, respectively. The recorded strain values at failure were also observed to be reduced upon CKD addition compared to untreated samples. Further reduction in failure strain was recorded due to increase of CKD addition ratio up to $15 \%$ and remains unchanged for higher ratios of 20 and 30\%. Sreekrishnavilasam et al,2007 reported similar trend of stress strain relation of unconfined CKD treated samples while the recorded UCS increasing ratios were relatively higher ranging to 54 and $80 \%$ for 8 and $20 \%$ CKD addition ratios for clay soil with low plasticity.

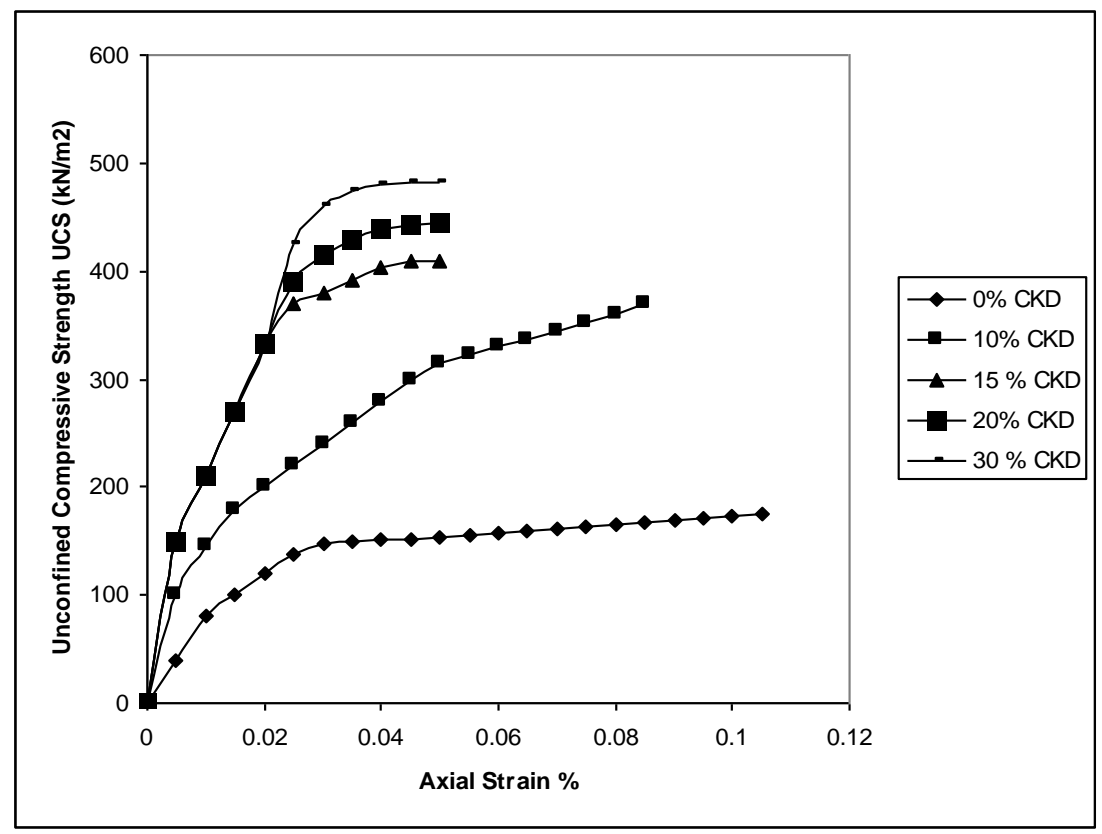

Fig. (2) Stress strain relation of untreated and treated samples with 10, 15, 20 and 30\% CKD at 28 days curing period.

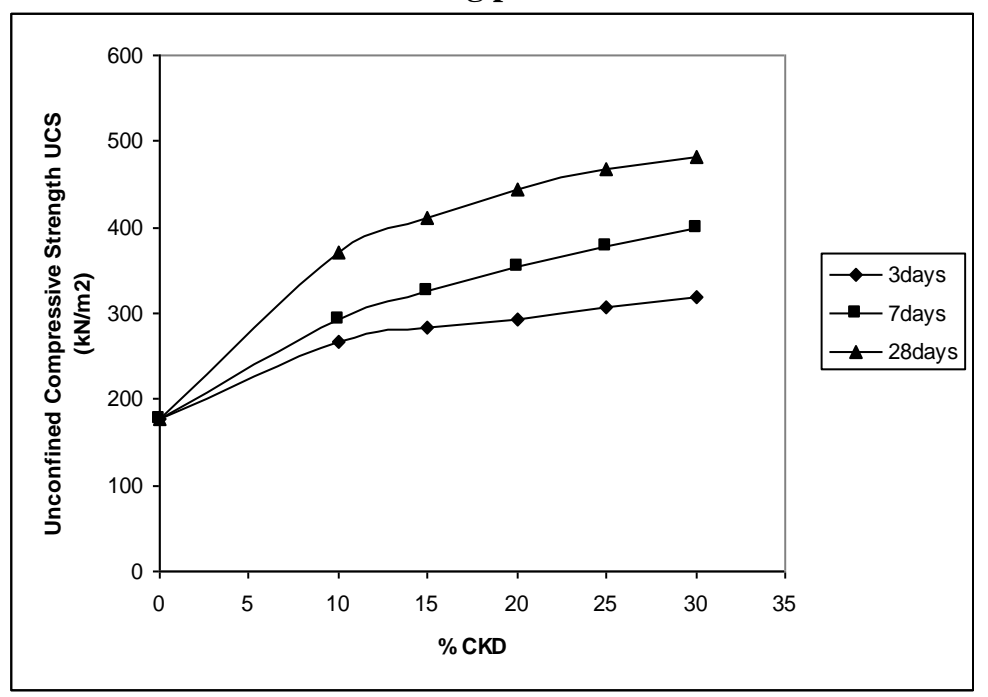

Fig.(3) Unconfined Compressive Strength untreated and treated samples with different CKD addition ratios at curing periods of 3,7 and 28 days. 
Figure(3) shows ultimate UCS values for untreated and treated samples with different CKD mixing ratios with curing periods of 3,7 and 28 days. As can be seen from this figure UCS of treated samples increases with increase of curing period. The percentage increase ranges from 52,66 and $110 \%$ at 3, 7 and 28 days, respectively compared to untreated samples at $10 \%$ CKD addition ratio. The corresponding ratios at 30\% CKD addition ratio are 81, 127 and $174 \%$.

\subsection{Direct Shear Strength}

Figures (4), (5) and (6) illustrate the results of direct shear test for samples with different CKD mixing ratios of 10, 15, 20,30\% at different curing periods of 3,7 and 28 days, respectively. As can be observed from these figures, addition of CKD to clay samples results in nearly doubling the angle of internal friction from $10^{\circ}$ to $21^{\circ}$ for different CKD addition ratios with no further increase with increase of curing period. Fig. (7) Illustrates direct shear cohesion with CKD mixing ratios for different curing periods of 3,7 and 28 days. As can be noticed from this figure samples cohesion increases about 20 times that of untreated sample at $10 \%$ mixing ratio with no further increase upon the increase of curing period. For the remaining addition ratios of 15,20 and $30 \%$ increasing ratios were 28,35 and 39 times untreated sample for addition ratios of 15,20 and $30 \%$. The corresponding increasing ratios at 7 days were 5, 7 and $16 \%$ times those at 3 days. These ratios were nearly doubled at 28 days.

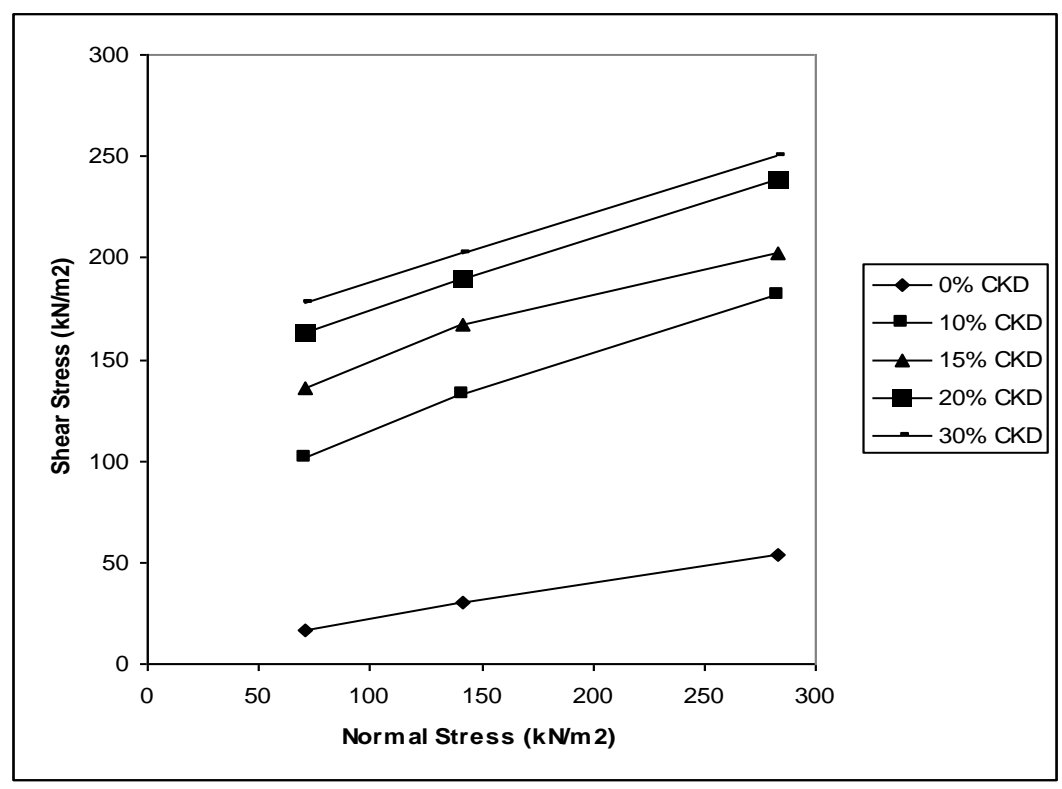

Fig. (4) Direct shear test results of samples with different CKD addition ratios of 0, 10, 15, 20 and $30 \%$ at

\subsection{Compaction Behavior}

3 days curing period.

Fig. (8) Illustrates compaction behavior of untreated and treated soil with different CKD mixing ratios. Typical compaction trend of different samples has been observed. As CKD was added to clay soil a reduction occurs in maximum dry density $\gamma_{\text {dmax }}$ (from 16 to $13.7 \mathrm{kN} / \mathrm{m}^{3}$ ) while optimum moisture content (OMC) increases (from 24 to $27 \%$ ) at $10 \%$ CKD addition ratio. For further increase in CKD addition ratios $\gamma_{\text {dmax }}$ slightly decreases to 13.5 and $13.3 \mathrm{kN} / \mathrm{m}^{3}$, while OMC increases to 37 and $47 \%$ for CKD addition ratios of 20 and $30 \%$, respectively. In literature this trend was associated with addition of a binder material to cohesive soil. 


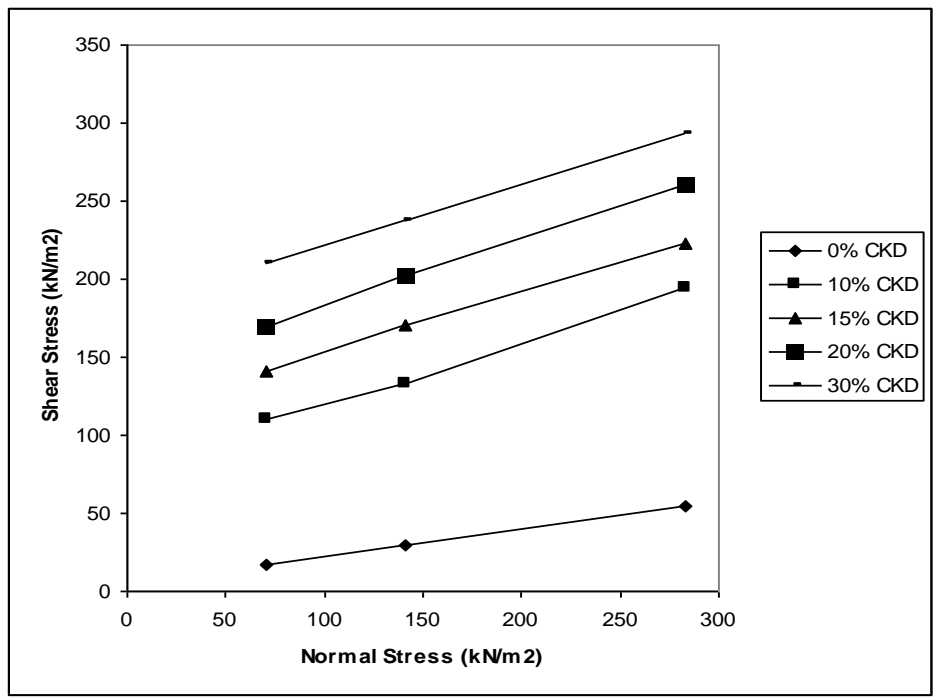

Fig. (5) Direct shear test results of samples with different CKD addition ratios of 0, 10, 15, 20 and $30 \%$ at 7 days curing period.

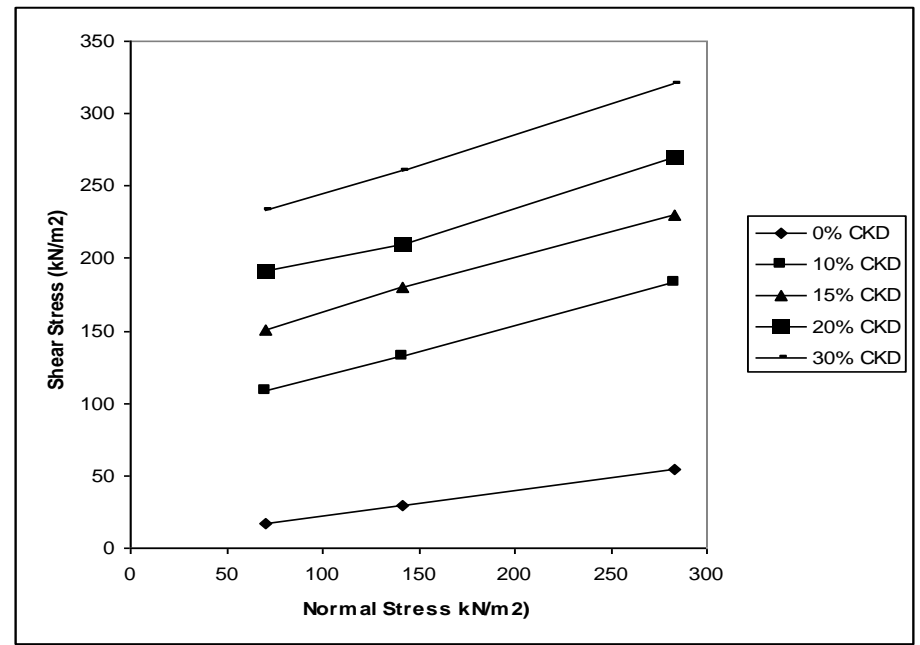

Fig. (6) Direct shear test results of samples with different CKD addition ratios of 0, 10, 15,20 and 30\% at 28 days curing period.

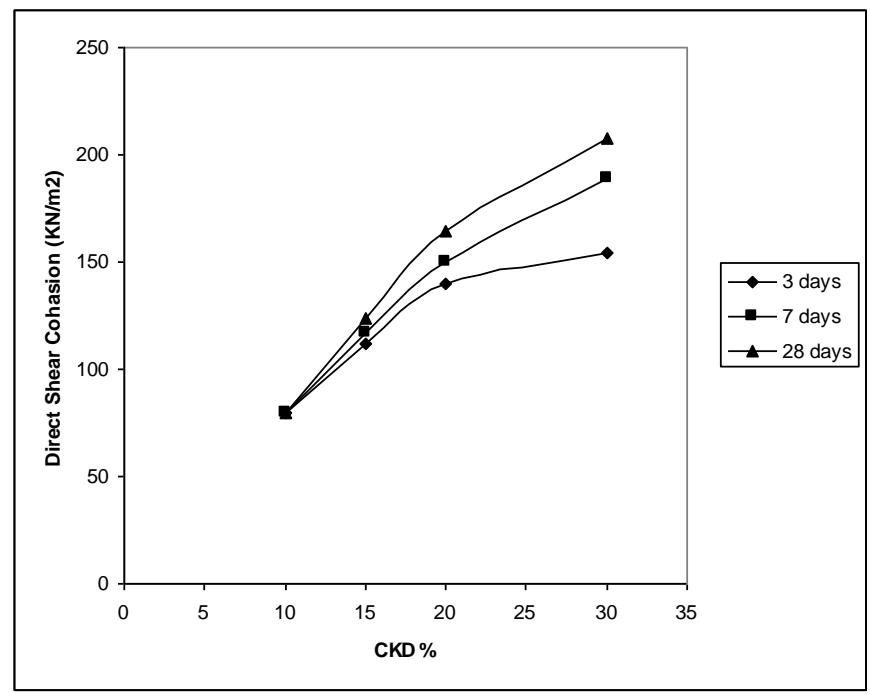

Fig. (7) Direct shear cohesion against CKD addition ratios at different curing periods of 3, 7 and 28 days. 


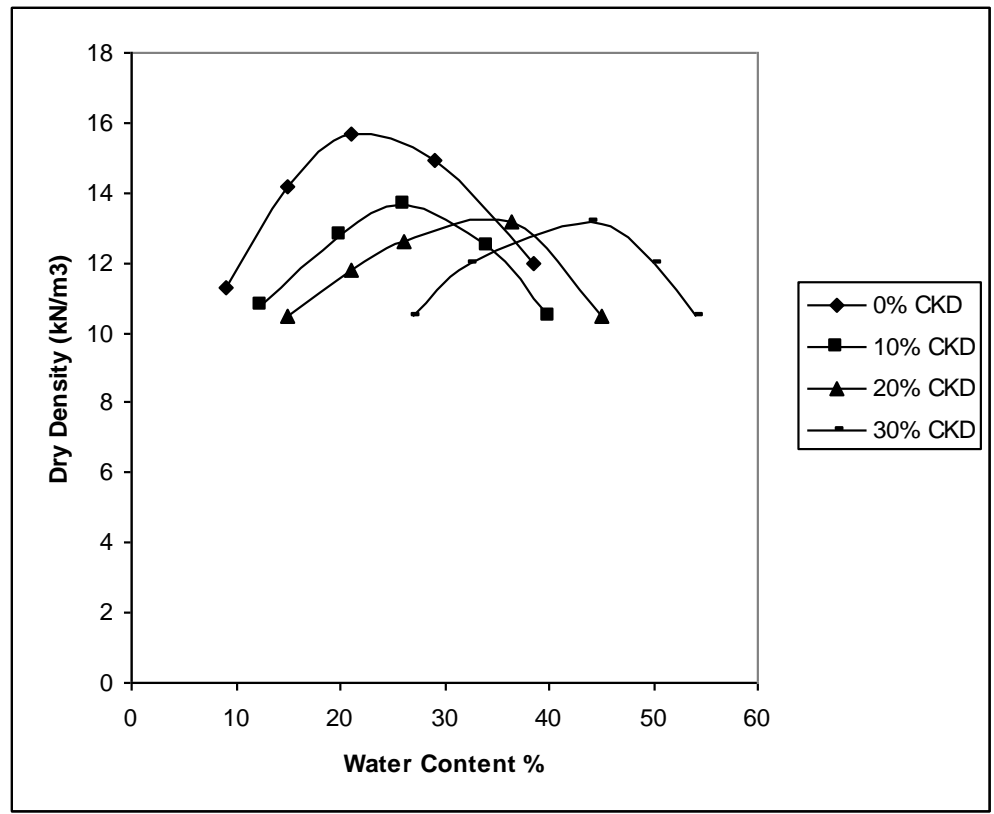

Fig. (8) Dry density vs. moisture content relationship of untreated and treated samples of different CKD addition ratios.

\subsection{X-Ray Diffraction Analysis}

The data sheets of hydrated CKD samples at 1, 7 and 28 days, in general indicated that hydration of CKD results in production of relatively high amount of calcium hydroxide $\mathrm{Ca}(\mathrm{OH})_{2}$ immediately at the first day after hydration. Amount of calcium hydroxide of hydrated CKD remains nearly unchanged for further curing periods of 7 and 28 days. However, negligible amounts of Ettringite $\mathrm{Ca}_{6} \mathrm{~A}_{12}\left(\mathrm{SO}_{4}\right)_{3}(\mathrm{OH}) 12.26 \mathrm{H}_{2} \mathrm{O}$,Syngenite $\mathrm{K} 2 \mathrm{Ca}(\mathrm{SO} 4) 2.2 \mathrm{H} 2 \mathrm{O}$ and absence of gypsum $\mathrm{CaSO}_{4}$ may be observed in hydrated samples of different curing ages. This may be attributed to the relatively small sulphate $\left(\mathrm{SO}_{4}\right)$ amount of unhydrated CKD. This may explain the relatively smaller enhancement unconfined compressive strength of CKD treated clay soil sample in present research compared to those observe in literature Peethamparan et al 2008 and Sreekrishnavilasam et al 2007, in which CKD of higher sulphate content were used. Quartz $\mathrm{SiO}_{2}$ and $\mathrm{Calcite} \mathrm{CaCO}_{3}$ peaks remained unchanged when comparing un-hydrated and hydrated CKD samples along different curing periods the matter that indicates that these compounds are inert against addition of water.

\subsection{Soil Permeability}

According to the falling head permeability tests the relationship between coefficient of permeability and CKD mixing ratio are as illustrated in Fig.(9). The recorded values of coefficient of permeability were $4.216,165.4,3470$, and $5359 * 10^{-7} \mathrm{~cm} / \mathrm{sec}$. From this figure it can be noticed that the coefficient of permeability of untreated clay soil is at the lower limits of poorly pervious soil which is within the range of silty clay mixtures of very low degree of permeability. Mixture of $10 \%$ CKD significantly increases the coefficient of permeability by a value of nearly 38 times its original value to the range of higher limits of poorly pervious soil. Further increase of CKD addition ratio to $15 \%$ increases coefficient of permeability by a value of nearly 351 times its original value. This increase passes to the lower limits of fairly pervious soil which corresponds to the range of fine sand of low permeability. Further increase of CKD addition ratio results in a corresponding increase of coefficient of permeability with increasing values of 950,1270 and 1327 for mixtures ratios of 20,25 and $30 \%$, respectively. As also indicated from Fig. (9), the rate of increase of coefficient of permeability corresponding to increase of CKD addition ratios above $20 \%$ is relatively small. Figures (10) and (11) illustrate a SEM image of a fractured sample surface of untreated and CKD treated clay soil samples up to $20 \%$ mixture ratio, respectively. In general the whitely shaded areas indicate their relative highly elevated level of fractured surface and the darkly shaded indicate their relative deepness. As for the untreated sample their surface appears as a 
sealed surface with no pores at this magnification scale. On the other hand the surface of treated sample appeared as a deformed surface with sharply edged grooves which indicate relatively high porosity of the sample.

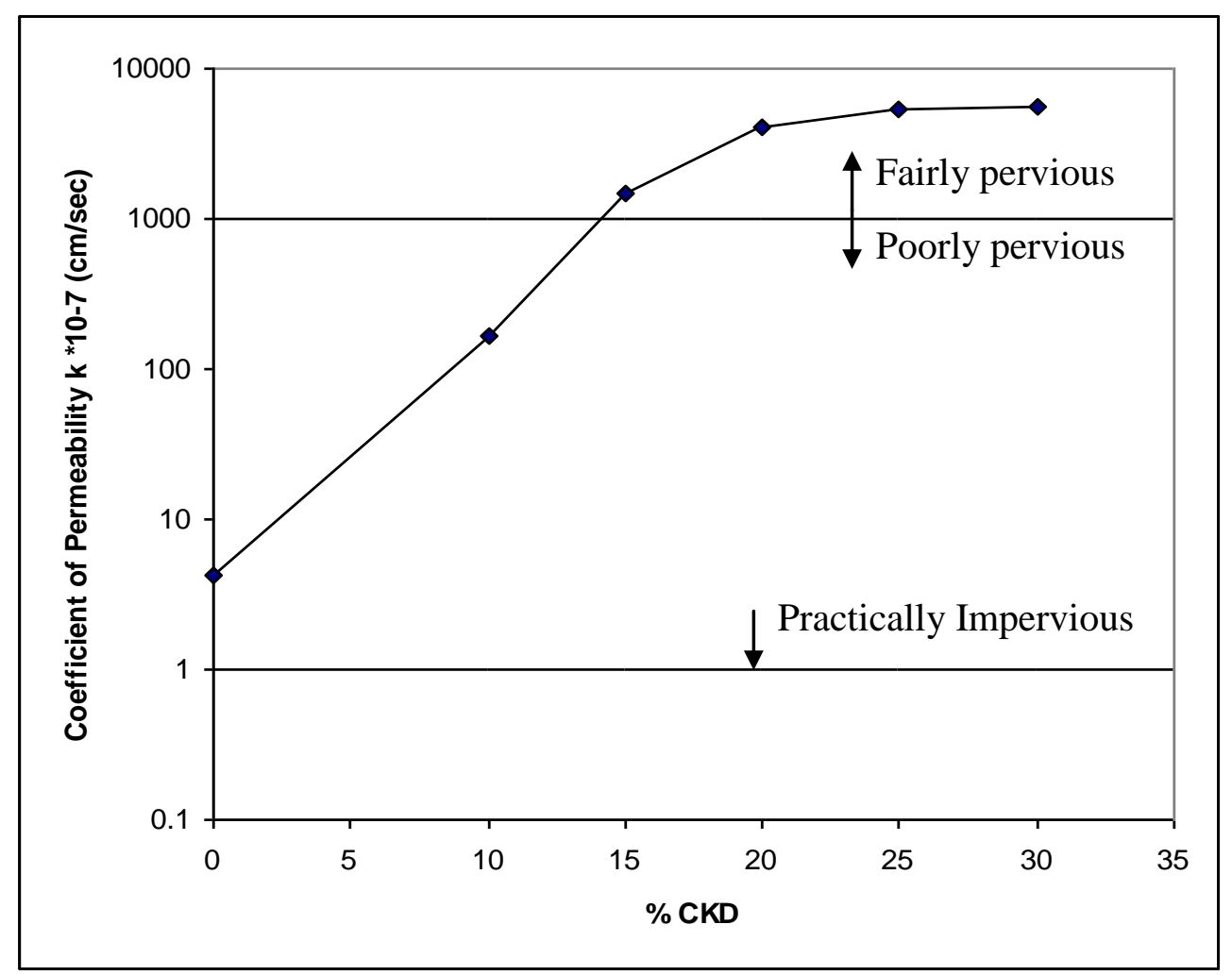

Fig. (9) Coefficient of permeability of untreated and treated samples with different CKD addition ratios.

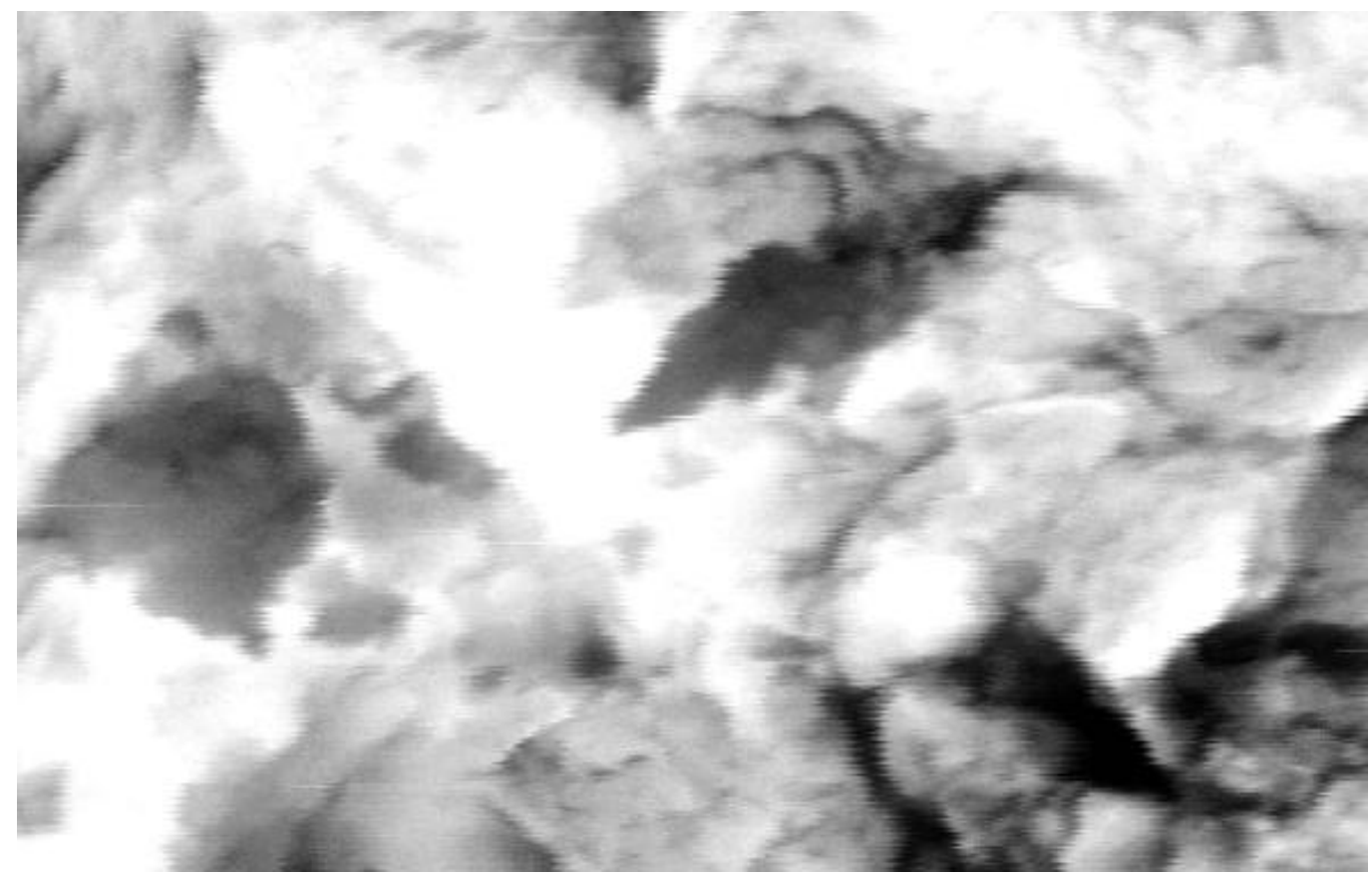

Fig. (10) Scaning Electron Microscope (SEM) image of untreated clay soil sample 


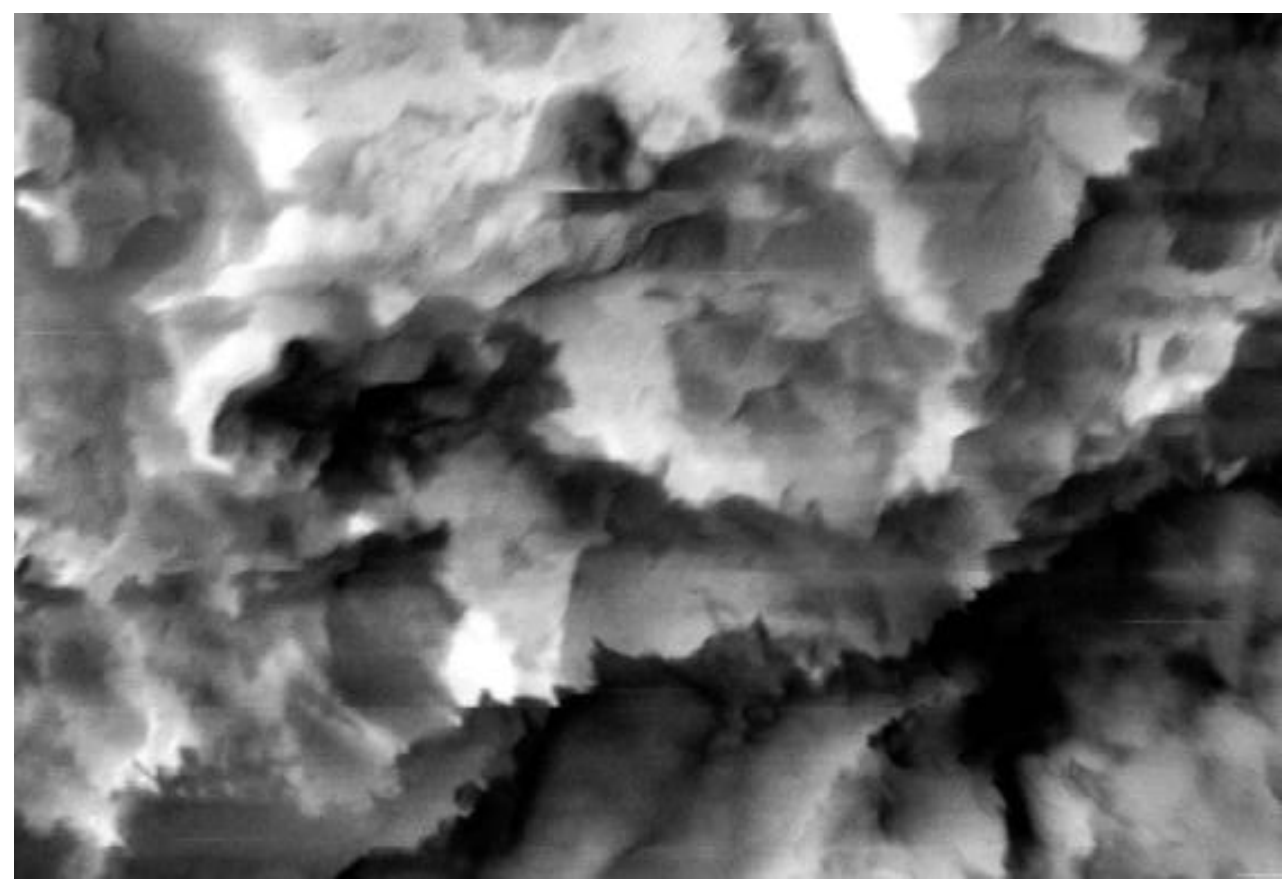

Fig. (11) Scaning Electron Microscope (SEM) image of treated clay soil sample.

\section{CONCLUSIONS}

Cement kiln dust (CKD) produced at Yanbu Plant is being used as land filled near by the plant causing economical and environmental challenge. A laboratory study was conducted to investigate the feasibility of using CKD as a soft clay sub-grade soil stabilizer. From this study it can be concluded that CKD produced at Yanbu cement plant may be used as a shallow and deep soft clay stabilizer due to that:

- It contains relatively high percentage of free lime content indicating its potential of conducting chemical reaction with clay minerals thus producing cementious compounds causing stabilization process.

- CKD addition to clay soil significantly improves consistency limits, stress strain relationship shear strength parameters, compaction behavior.

- Unconfined compressive strength and shear stress parameters for CKD treated soil samples increases with increase of curing period.

The compound responsible for strength gaining upon hydration of CKD under study is calcium hydroxide which is highly produced due to relatively high free lime content.

- To increase the ability of producing cementious compounds such as Ettringite and Gypsum upon hydration of CKD amount of sulphate may be increased.

- $\quad$ CKD additing to clay soil significantly improves permeability of the clay soil, which indicates the ability of using it for accelerating consolidation process.

\section{REFRENCES}

- Aheln D L, Hastings R J, Sexhreiber R J, Yonleg C. Detailed illustration of contingent management for cement kiln dust. In: Research and development bulletin, SPIIST.

Skokie (IL): Portland cement Association; 1993.

- Alawi M.H., 2000, " Design and Performance of Rut Resistant Asphaltic Concrete Mixture", $\mathrm{PhD}$

Thesis, Leeds University, Leeds, UK.

- Baghdadi; Z A. Utilization of kiln dust in clay stabilization. Journal of Engineering

Science, Jeddah, Scientific publication Center, King Abdul Aziz University, 1990.

- Baghdadi Z A, Fatani N, Sabban N A. Soil modification by cement kiln dust. J Mater Civil Eng. ASCE 1995; 7.

- Bowles J E, " Engineering properties of soils and their measurement" McGraw-Hill Book Co, New York, N.Y. 1978.0 
- Data Sheets of X-Ray diffraction analysis of CKD of Ynbu cement plant, Ynbu, KSA.

- Dyer T D, Halliday J E, Dhir R K. An investigation of the hydration chemistry of ternary blends containing cement kiln dust. J Mater Sci 1999; 34 (20): 4975-4985.

- Hilt G H, Davidson D T. Lime fixation in clay soils. Highway Resh. Bull. 1960; 262: 20-32.

- McCoy W J, Kriner R W. Use of waste kiln dust for soil consolidation. Allen tower (PA): Lehigh Portland Cement Co., 1971.

- Miler GA, Azad S. Influence of soil type on stabilization with cement kiln dust. Construct Build Mater 2000; 14(2): 89-97.

-Peethamparan S, Olek J, and Lovell J. Influence of chemical and physical characteristics of cement kiln dusts (CKDs) on their hydration behavior and potential suitability for soil stabilization ELSEVIER. Cement and Concrete Research, 2008; 38: 803-815.

-Sreekrishnavilasam A, Rahardja S, Kmetz R, and Santagata M. Soil treatment using fresh and land filed cement kiln dust. ELSEVIER, Constructional Building Materials, 2007; 21: 318-327.

-Zaman M, Laguros J G, Sayah A. Soil stabilization using cement kiln dust. In:

Proceedings $7^{\text {th }}$ international conference on expansive soils, Dallas, TX; 1992: 347 351. 